Affordable, quality health care. For everyone.

\title{
Findings from a \\ Survey of Health Care Delivery Innovation Centers
}

$$
\text { April } 2015
$$

Sarah Klein, Martha Hostetter, Douglas McCarthy, and Susan Hayes 


\section{What Is a Health Care Delivery Innovation Center?}

We defined innovation centers as places

that are working to discover, develop, test, and/or spread new models of care delivery -in hospitals, clinics, and patients' homes.

The innovations they test may be internally developed or adopted from elsewhere. 


\section{Survey Methods}

- We conducted a survey of health care delivery innovation centers affiliated with health systems to learn about their potential role in promoting health system transformation. Survey respondents were identified via scanning, expert recommendation, and snowball sampling.

- The online survey was conducted between November 2014 and January 2015. Survey included 25 questions about the structure, focus, and staffing models of these innovation centers, as well as the competencies, resources, and time needed to do their work.

- We received responses from 36 centers of 67 invited survey participants. We excluded three respondents that had not yet officially launched their centers or were not affiliated with a health care delivery system, bringing the final sample to 33 . 


\section{Fast Facts About Innovation Centers Surveyed}

\begin{tabular}{|l|c|c|}
\hline Question & Range of Responses & Median \\
\hline Year started & $1995-2014$ & 2010 \\
\hline $\begin{array}{l}\text { Annual budget } \\
\text { (when disclosed) }\end{array}$ & $\$ 150,000-\$ 18,000,000$ & $\$ 1,950,000$ \\
\hline $\begin{array}{l}\text { Number of staff } \\
\text { (full-time equivalents) }\end{array}$ & $1-215$ & 6 \\
\hline $\begin{array}{l}\text { Time spent testing } \\
\text { an innovation }\end{array}$ & 1 week-3 years & $3-12$ months \\
\hline $\begin{array}{l}\text { Number of innovations } \\
\text { being tested }\end{array}$ & $2-100$ & 12.5 \\
\hline Time horizon for funding & 1 year-10 years & 1 year \\
\hline
\end{tabular}




\section{How Do Centers Define Innovation?}

- Doing things differently versus doing them better.

- Emerges when you view a problem through the eyes of the patient rather than the provider or the institution.

- Requires collaborations among industry partners, technology developers, health care leaders, clinicians, and patients.

- Dramatically improves health and health outcomes and reduces spending and as such requires widespread adoption. 


\section{What Do Innovation Centers Do?}

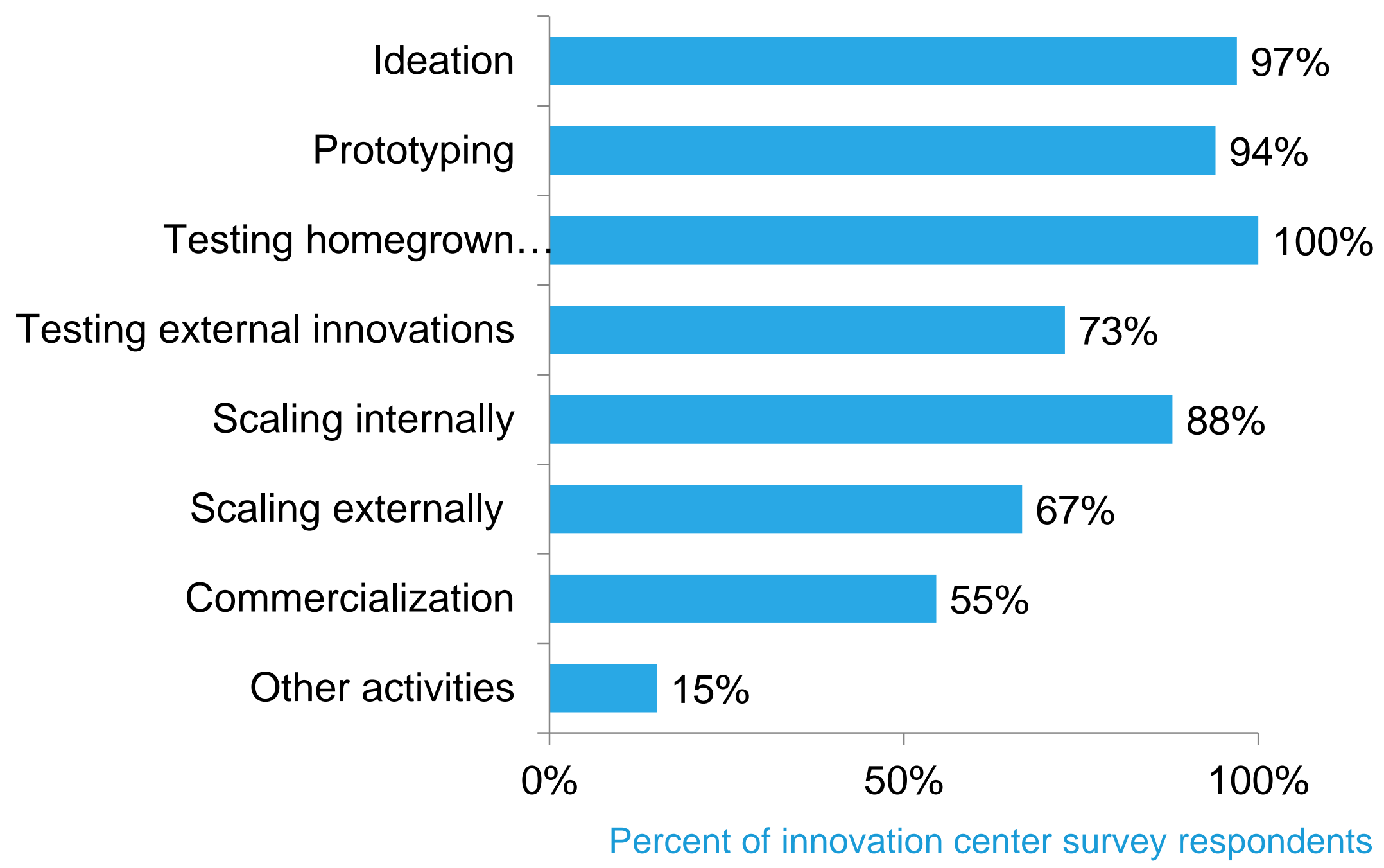

Notes: Percentages based on 33 innovation center respondents. Other activities include providing consulting services, scanning for innovations globally, building/encouraging an innovative culture within home institution, providing seed funding for internal ideas, and use of simulation for prototyping. 


\section{What Do Innovation Centers Focus on?}

Care coordination Disease-specific outcomes Access Patient engagement Workflow efficiencies

Population health Clincal decision support Intraprofessional communication

Utilization Home-based care Wellness Patient safety Devices Community-based services Price transparency Other responses

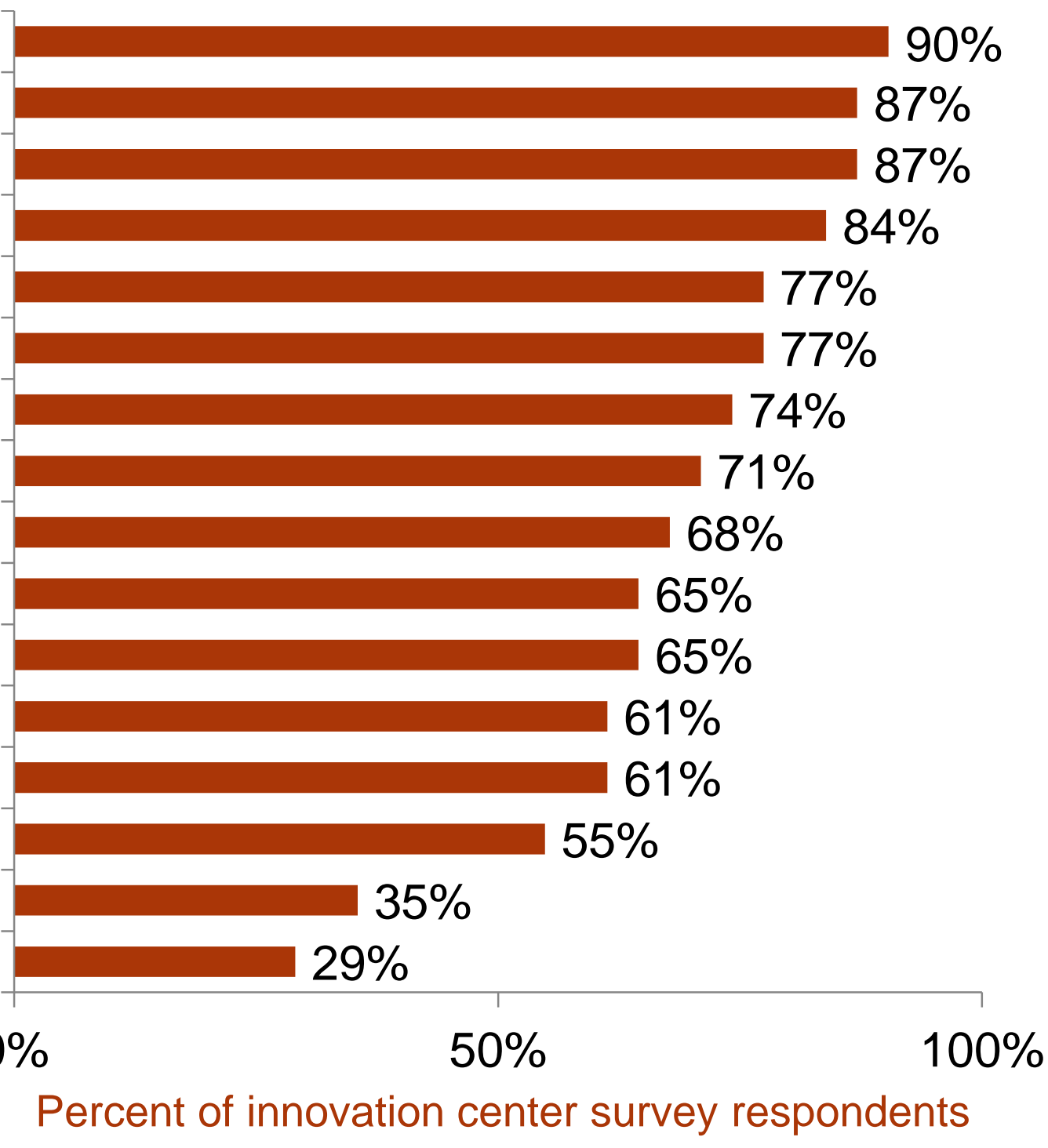

Notes: Percentages based on 31 innovation center respondents. Other responses include spending reductions, the uninsured, helping seniors age in place, teaching/education, data mining, and data analysis. 


\section{Which Groups Do Innovation Centers Partner with in Their Work?}

Frontline providers Software developers Patients Product designers Entrepreneurs/startups Private payers Foundations Pharma/device makers Venture capital firms Public payers

External accelerators Other innovation centers Other

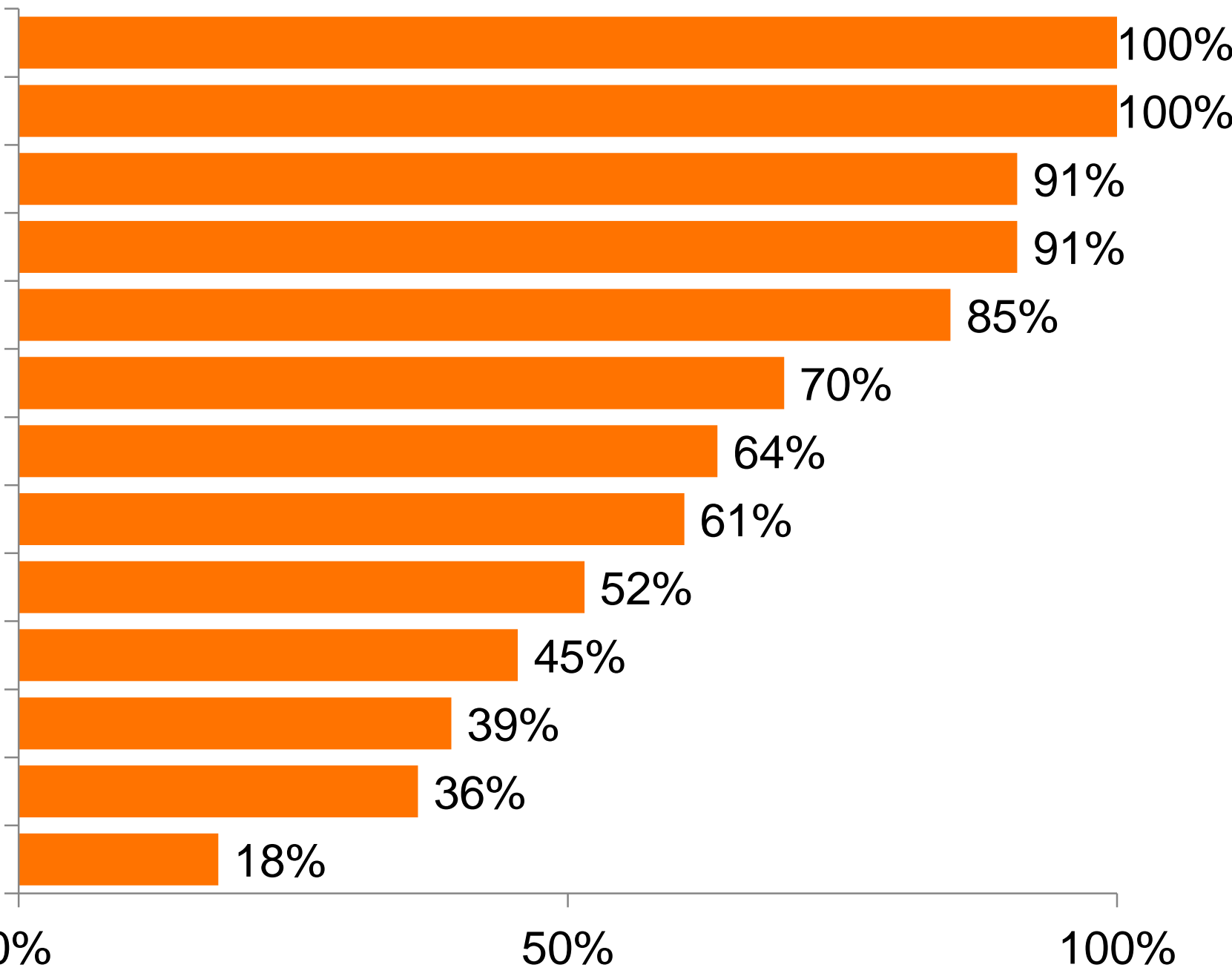

Percent of innovation center survey respondents

Notes: Percentages based on 33 innovation center respondents. Responses reflect collaboration with group at any stage or phase of work (ideation, development, testing, or spread). Other partners include higher education, biomedical researchers, the National Institutes of Health, nonprofits, and public companies not specifically focused on health care as their core business. 


\section{Which Frontline Providers Do Innovation Centers Engage with?}

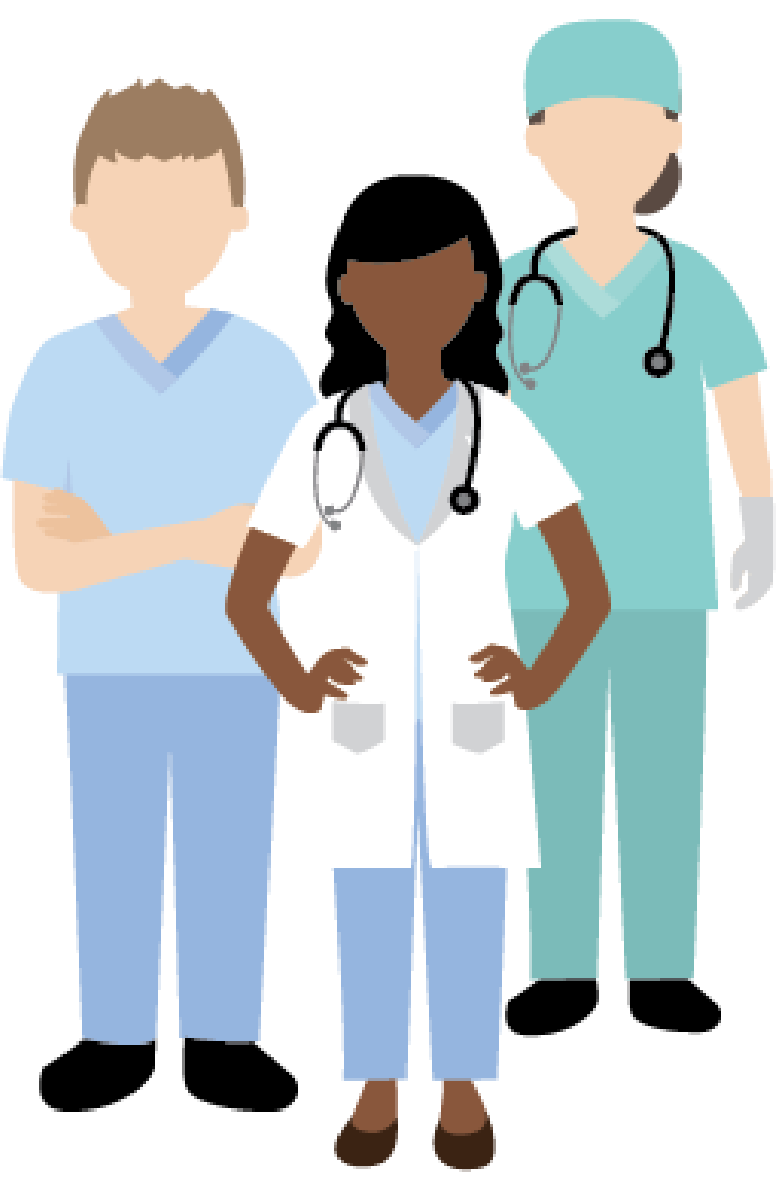

Percent of innovation center survey respondents

$100 \% \quad 90 \% \quad 87 \% \quad 84 \%$

$68 \%$

$61 \% 61 \%$

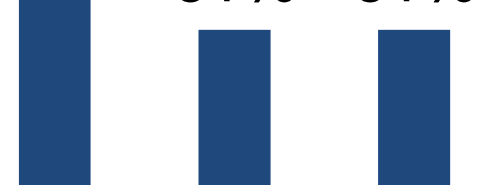

$26 \%$
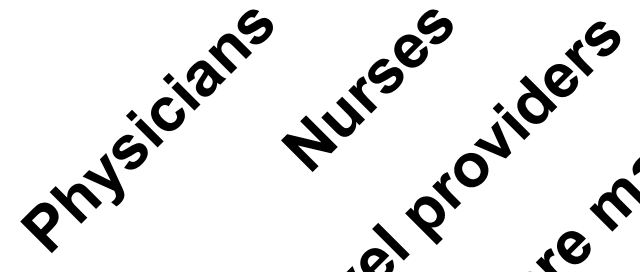

p
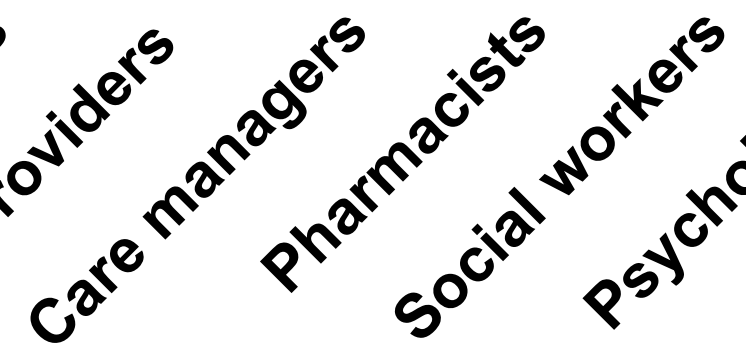

$00^{5 s^{5}}$

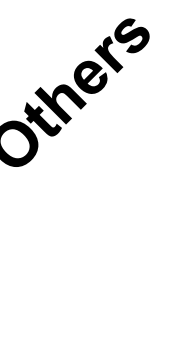

Notes: Percentages based on 31 innovation center respondents. Mid-level providers include physician assistants and nurse practitioners. Others include patient care techs, wellness coordinators, infection control staff, environmental services staff, physical and occupational therapists, nutritionists, coaches, and navigators. 


\section{Which Health Care Settings Do Innovation Centers Target?}

Percent of innovation center survey respondents $100 \%$

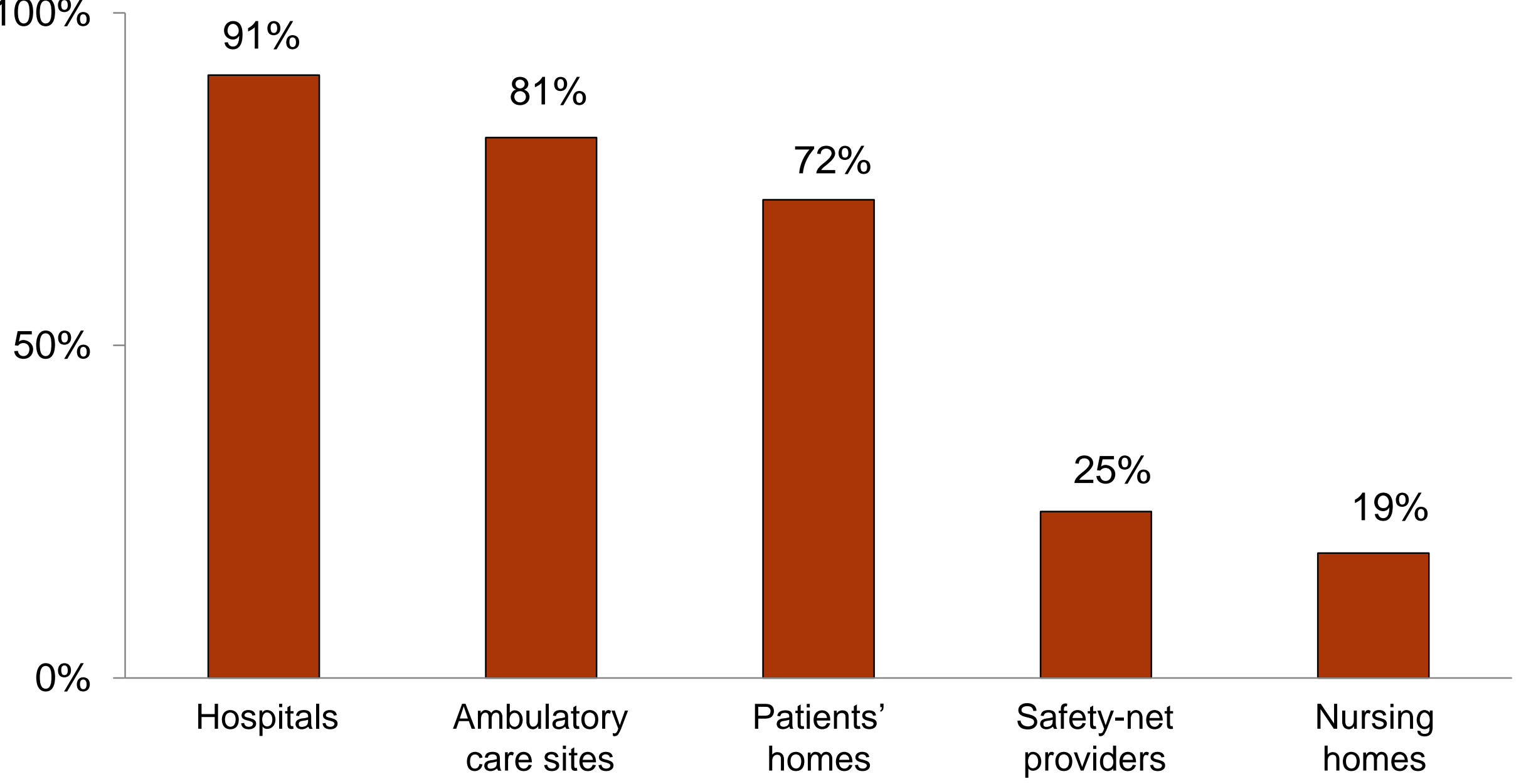




\section{What Strategies and Sources Do Innovation Centers Use to Identify Potential Innovations?}

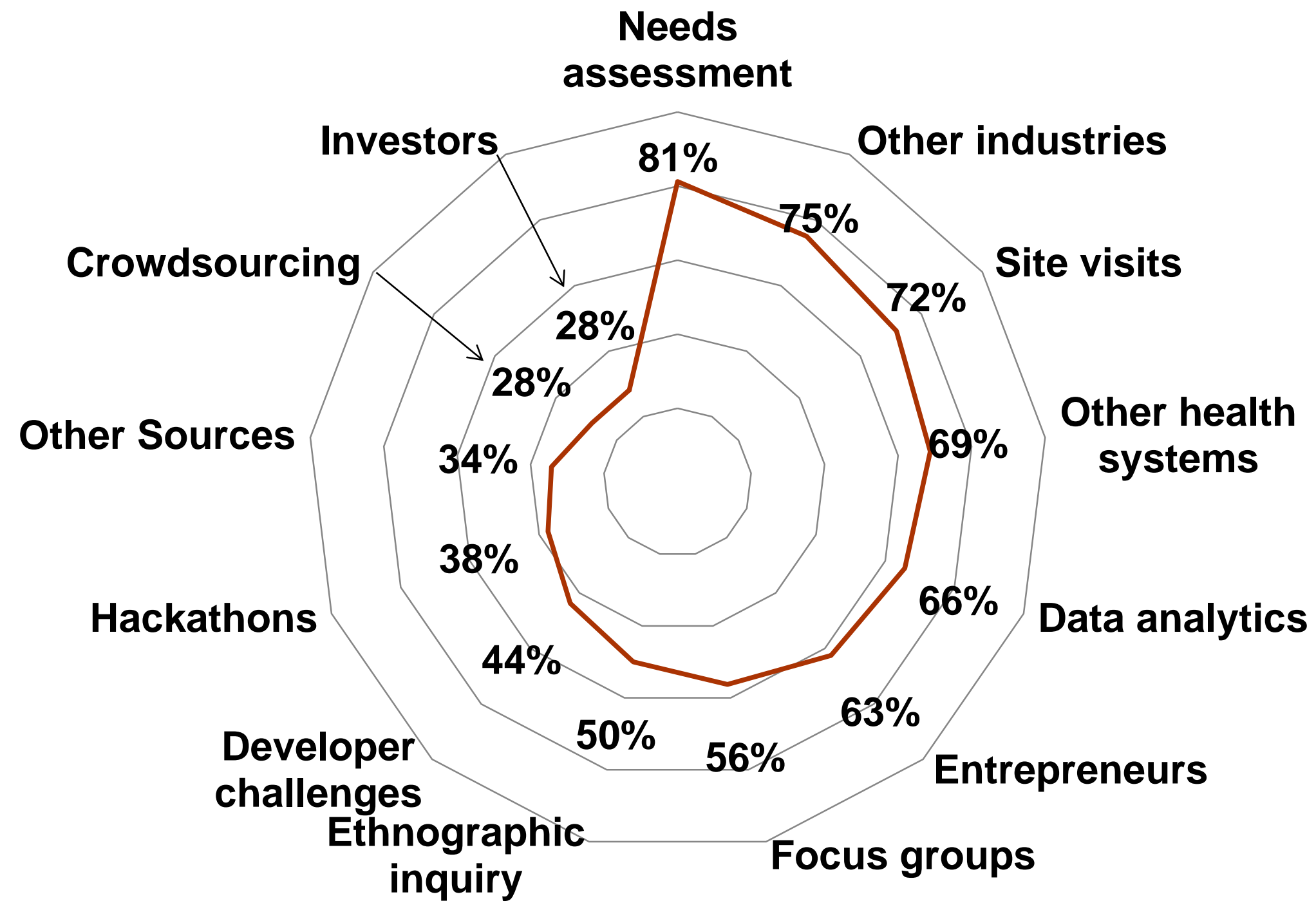




\section{How Do Innovation Centers Decide Whether a Project Is Worth the Investment?}

Percent of innovation center survey respondents

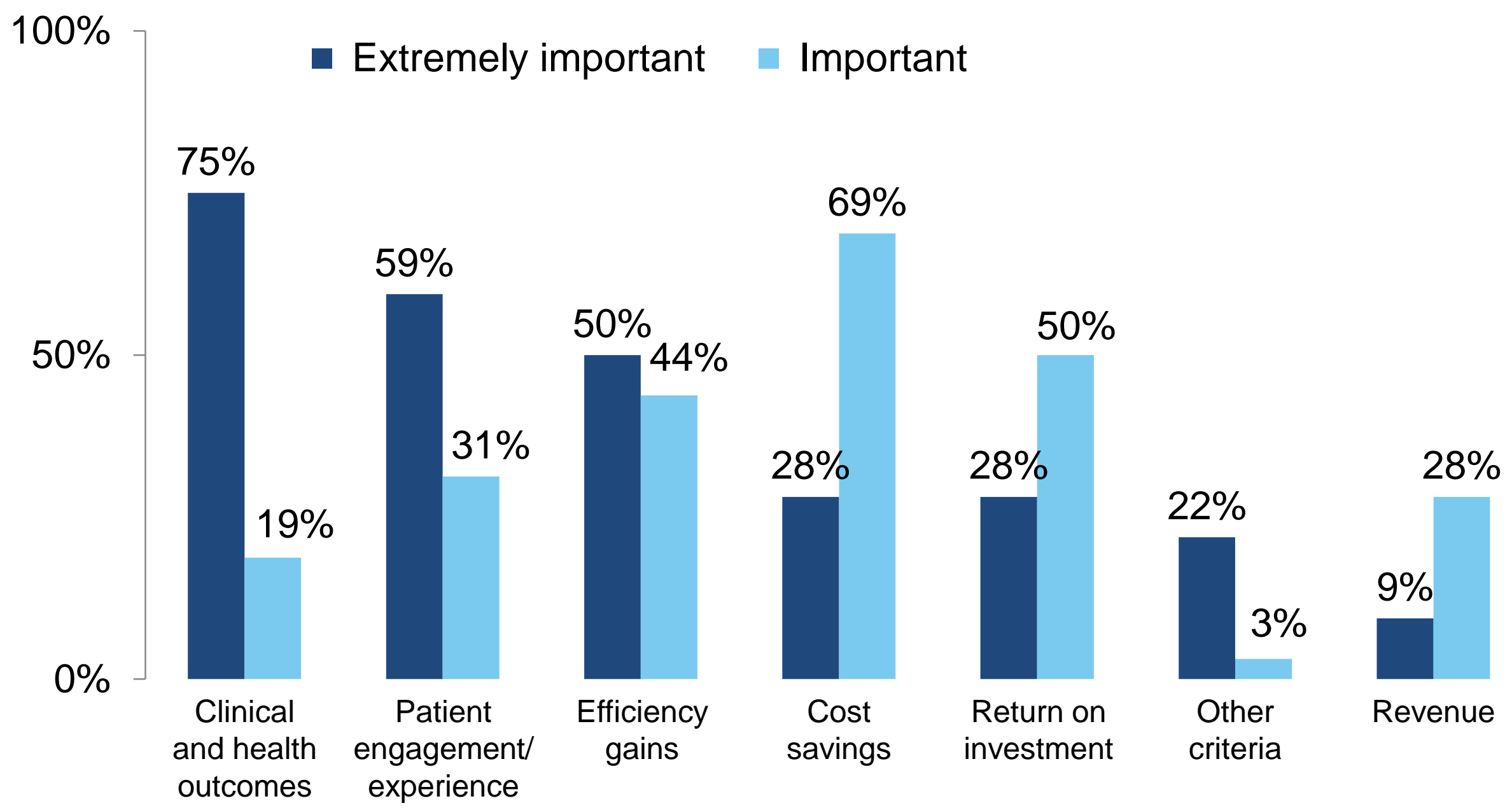

Notes: Percentages based on 32 innovation center respondents. Other criteria include formal cost/benefit analysis, speed to impact, alignment with organizational strategy and customer needs, research value, executive and clinical support, improvement in physician satisfaction or value to provider, and solving a clearly identified need. 


\section{Which Digital Technologies Do Innovation Centers Commonly Employ?}

Percent of innovation center survey respondents $100 \%$ 94\% $91 \% \quad 91 \%$ Electronic menacalie

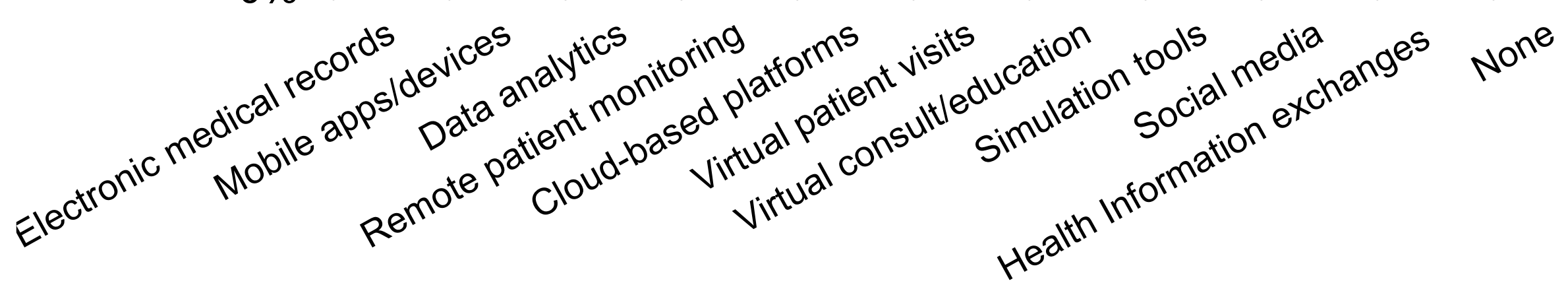

Notes: Percentages based on 32 innovation center respondents. Virtual consult/education refers to interprofessional consultation/education. 


\section{What Barriers Do Innovation Centers Encounter?}

\section{- Major barrier Minor barrier}

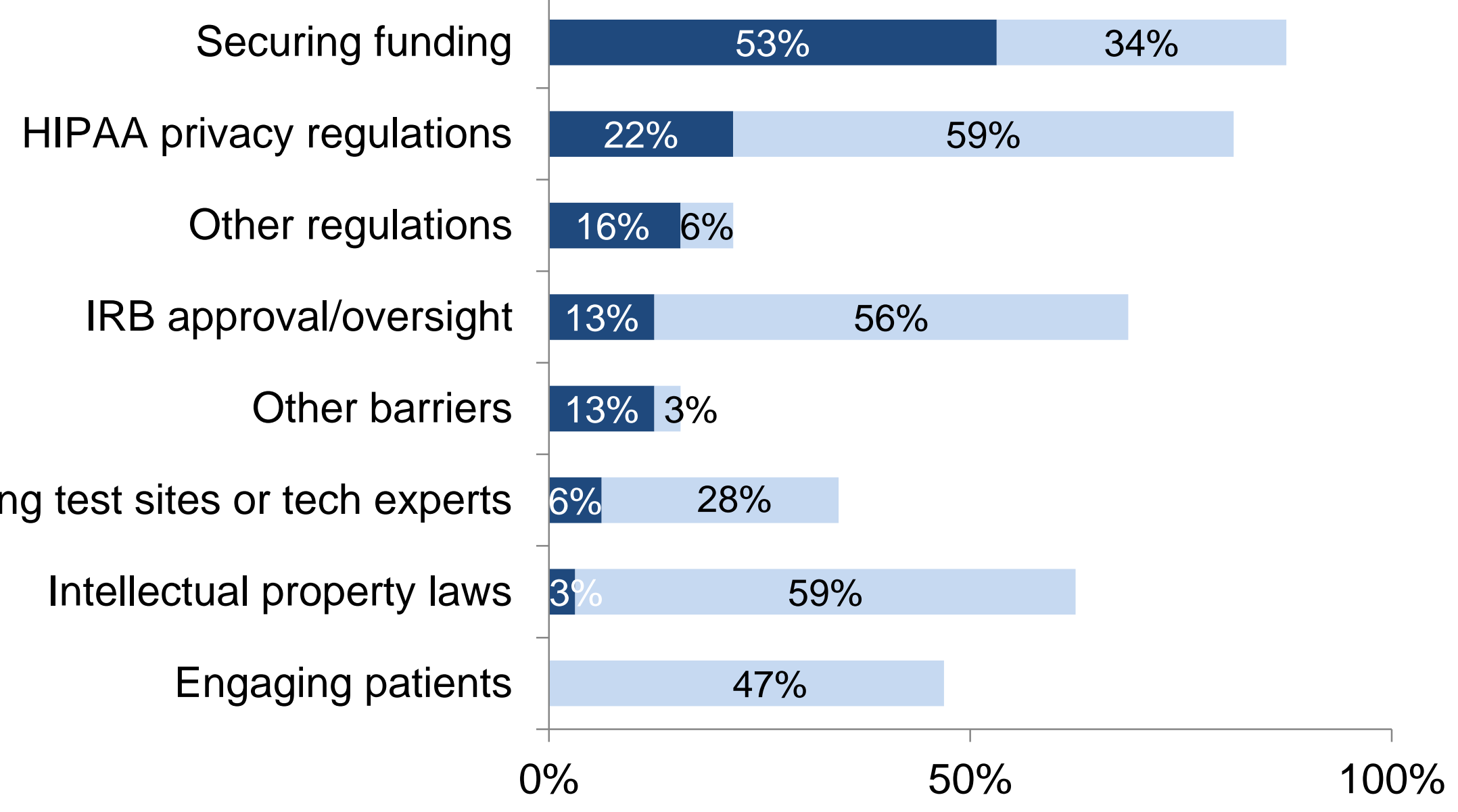

Percent of innovation center survey respondents

Notes: Percentages based on 32 innovation center respondents. IRB = Institutional Review Board. Other regulations noted as barriers included scope of practice laws, Food and Drug Administration regulations, telehealth licensing, and staffing ratios. 


\section{Do Innovation Centers Focus on Vulnerable Populations?}

\section{Percent of innovation center survey respondents}

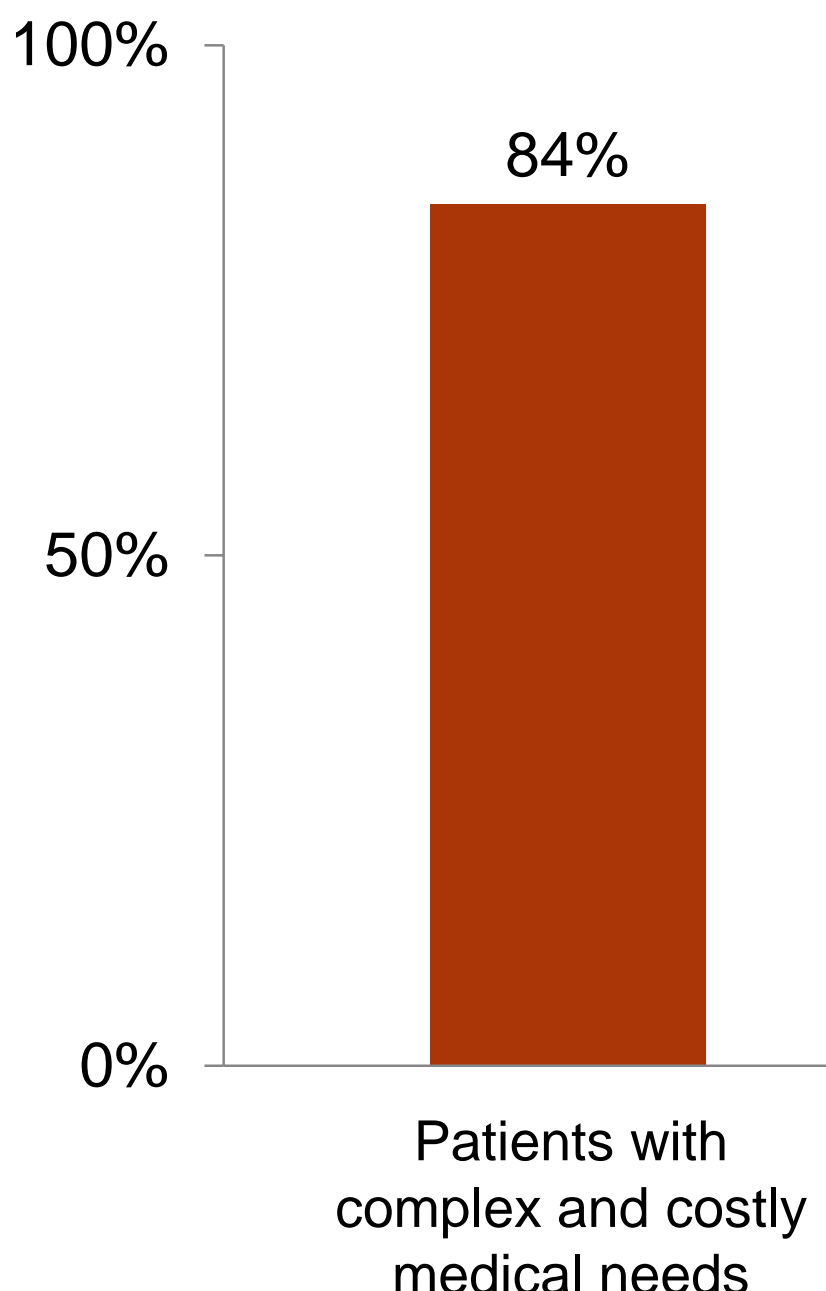

$72 \%$

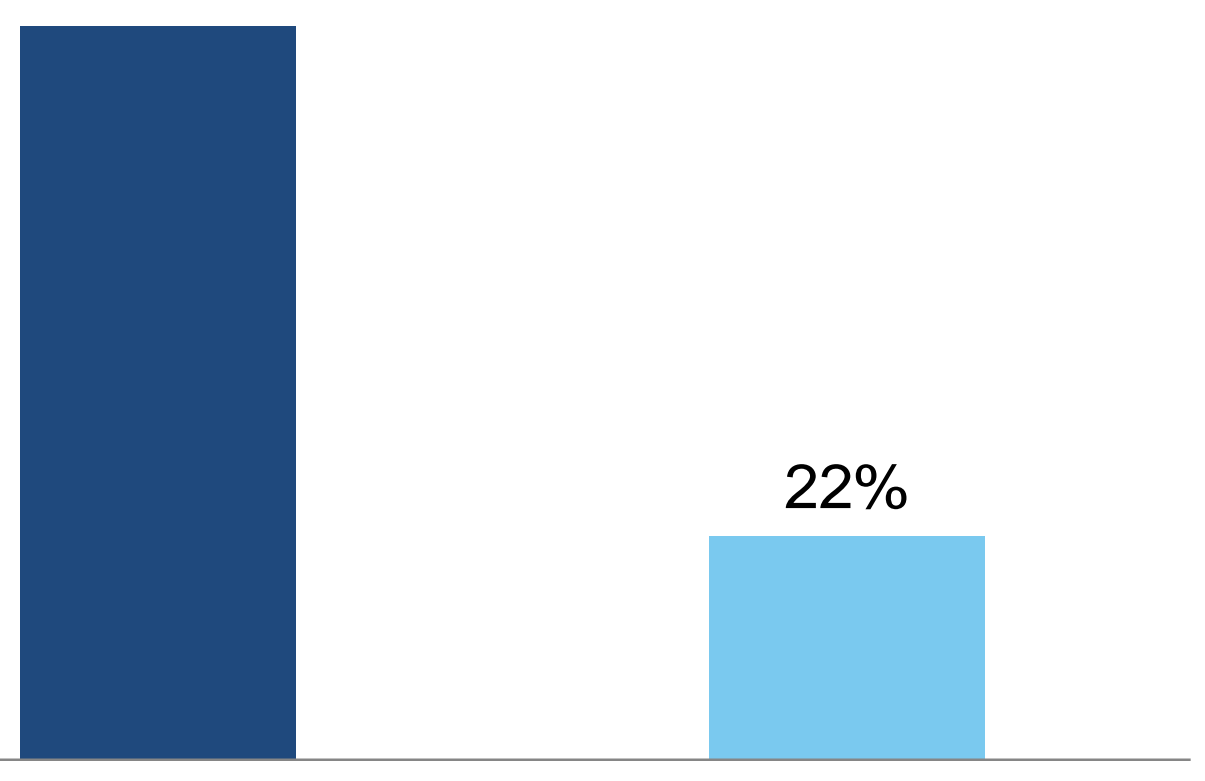

Notes: Percentages based on 32 innovation center respondents. Other vulnerable populations include residents of rural communities, the mentally ill, the elderly, and the working poor.

People with unmet social needs
Other vulnerable populations 


\section{How Are Innovation Centers Funded?}

\section{Percentage of Budget from Home Institution}

- $1-24 \%$

- $25-49 \%$

-50-74\%

- $75-100 \%$

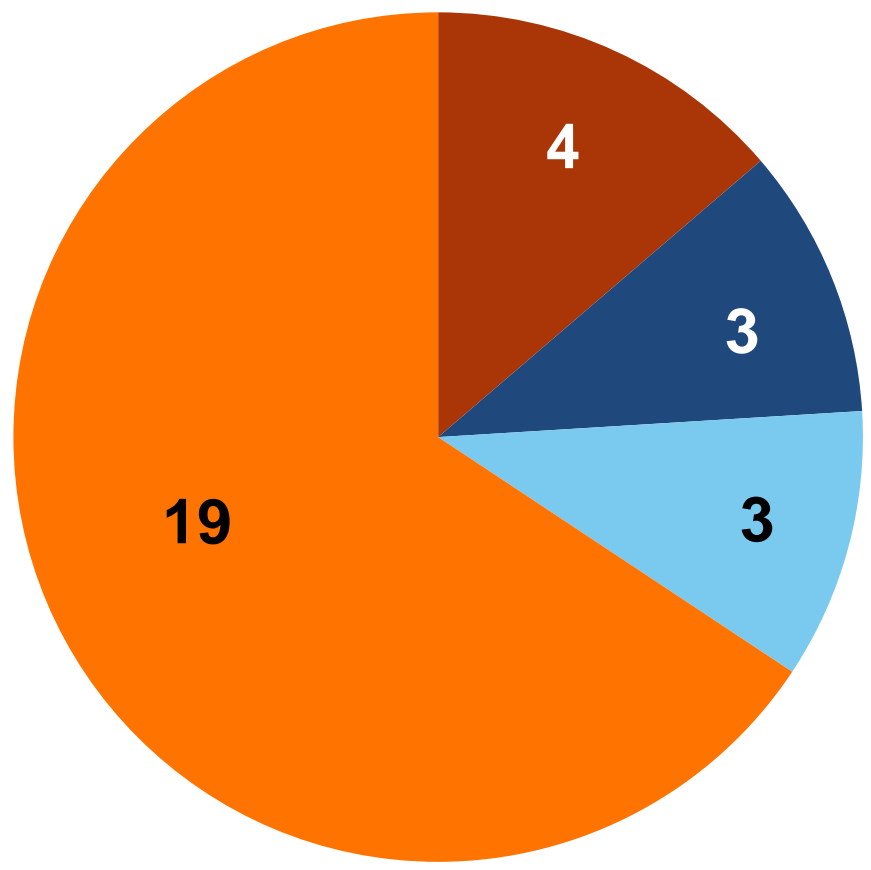

Number of innovation center survey respondents

\section{Other Funding Sources}

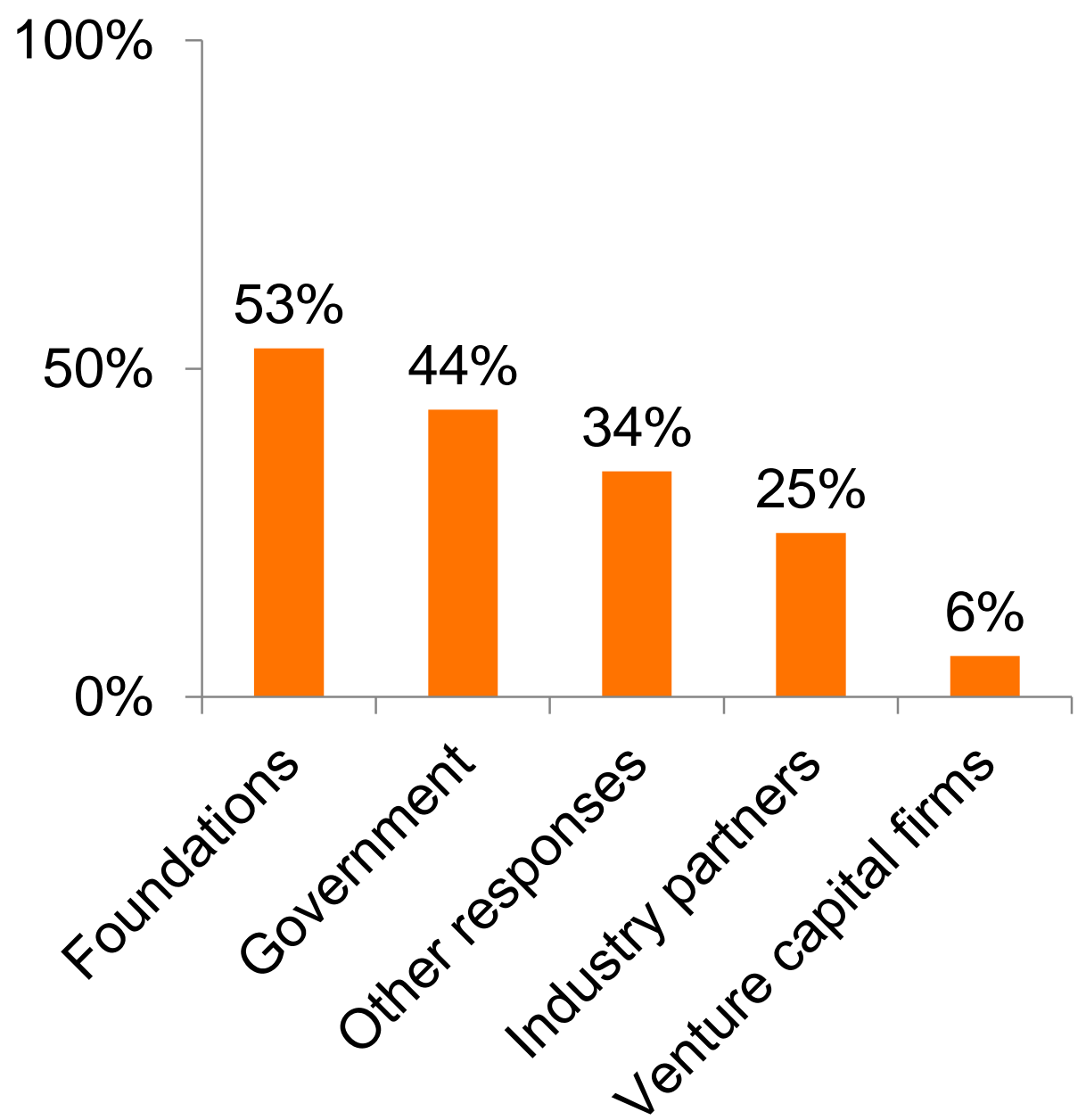

Notes: Percentages for pie chart based on 29 innovation center respondents; percentages for bar chart based on 32 innovation center respondents. Other responses include individual donors, universities, health insurers, and health care systems. We defined industry partners as medical device makers, pharmaceutical companies, and technology firms. 


\section{What Competencies Are Key to the Success of Innovation Centers?}

Lay a foundation

- Establish guiding values and vision

- Obtain organizational support and buy-in

- Set priorities, manage projects, measure performance

- Leverage health information technologies and analytics

\section{Discover, Design, Test}

- Discover ideas to address needs and improve value

- Understand the context for innovation (e.g., clinical workflows, payment)

- Apply human-centered design principles

- Use multiple methods to develop and rapidly test ideas

\section{Build relationships}

- Draw on subjectmatter experts (e.g., medicine, economics, engineering)

- Develop multidisciplinary teams that reflect diverse perspectives

- Make the most of collaborative relationships 


\section{Implications}

- While innovation centers have the potential to contribute to health system transformation, they will need sustainable funding and integration into clinical enterprises to succeed.

- Innovation centers may also benefit from collaborating with one another to identify solutions to common problems and develop a mechanism for spreading their work. 


\section{APPENDIX: EXAMPLE PROJECTS}




\section{Patient Engagement and Monitoring}

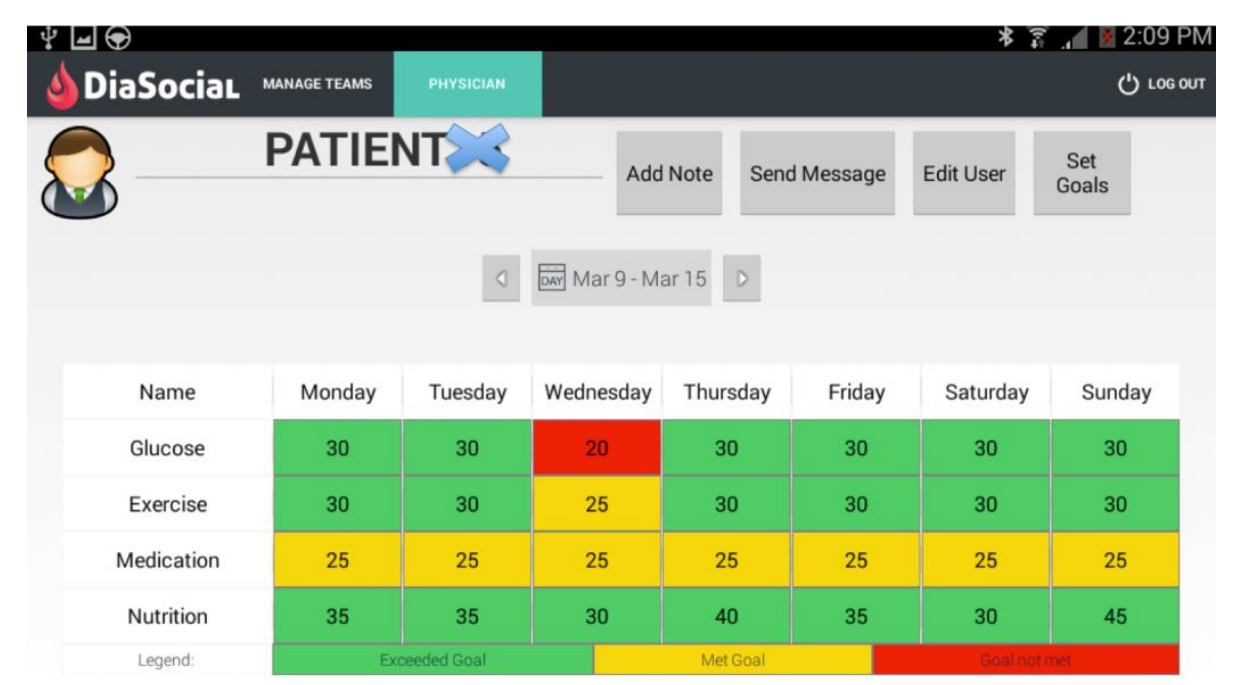

"Automated hovering" program that aims to improve medication adherence for patients following heart attack through: 1) automated tracking and reminders through wireless-enabled pill bottle, 2) daily sweepstakes, with winning conditional on adherence, 3) support from friends/ family members, and 4) support from social workers. Center for Health Care Innovation, University of Pennsylvania
Tablet-based program using motivational psychology to help diabetes patients record their care regimens, track goals, communicate with health coaches and peers, and visualize their health status both as individuals and as teams. Center for Health Information and Decision Systems, University of Maryland

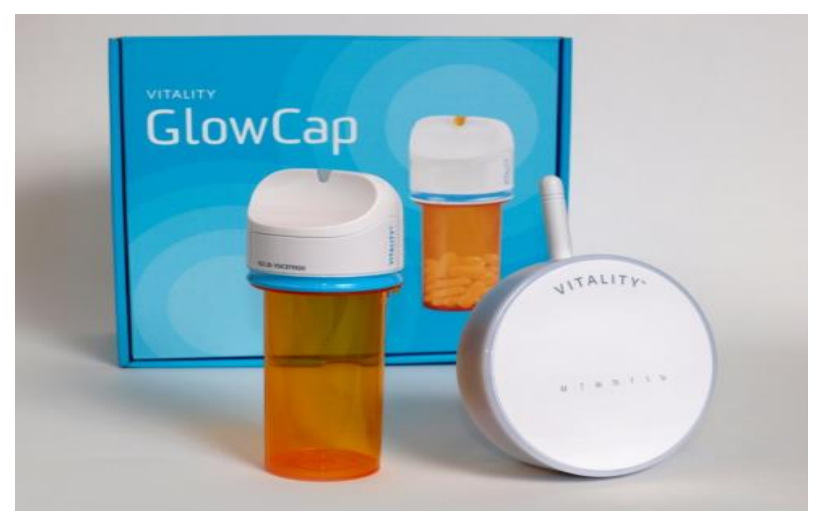




\section{Patient Engagement and Monitoring}

Remote monitoring program that enables continuous chronic disease management for patients with heart failure, hypertension, and diabetes. Patients use devices to monitor their health data (e.g., blood pressure, blood glucose

level, or weight) and share them with their primary care providers.

Center for Connected Health, HealthPartners
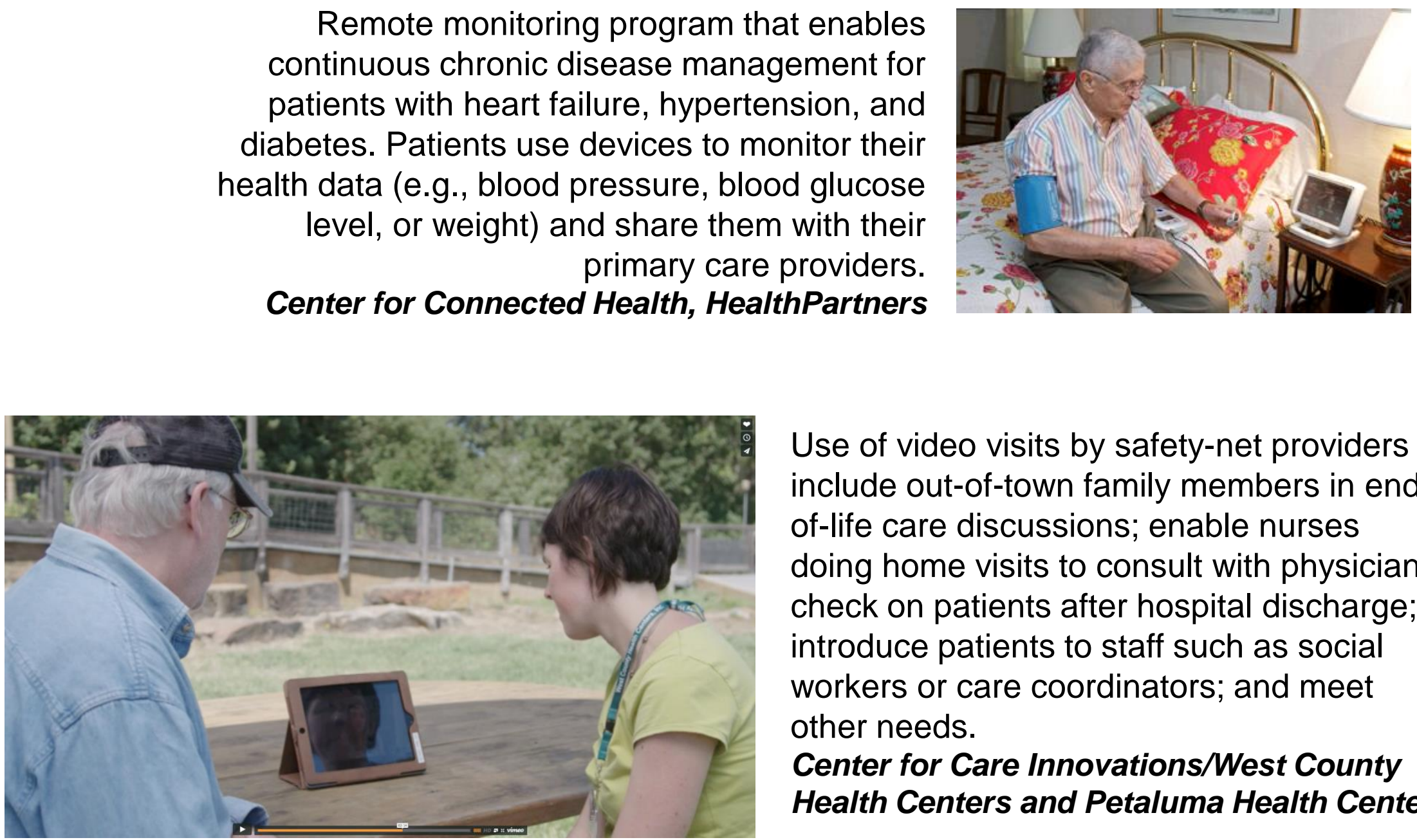

Use of video visits by safety-net providers to include out-of-town family members in endof-life care discussions; enable nurses doing home visits to consult with physicians; check on patients after hospital discharge; introduce patients to staff such as social workers or care coordinators; and meet other needs.

Center for Care Innovations/West County Health Centers and Petaluma Health Center 


\section{Care Coordination}

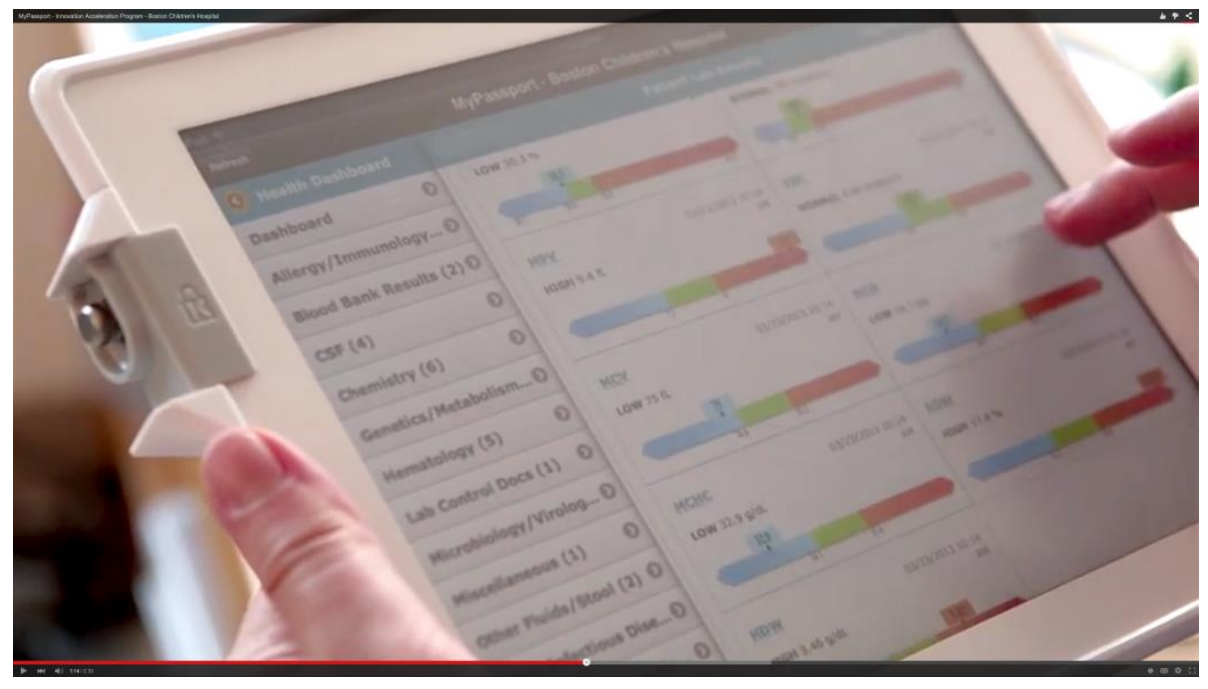

The Uploader mobile app lets diabetics send data from devices such as blood glucose meters, continuous glucose monitors, and insulin pumps to the cloud. The Blip app visualizes diabetes data to make it easier to see patterns and trends. Both were created on Tidepool, open-source software for creation of diabetes management tools.

Center for Digital Health Information, University of San Francisco, and Tidepool
The MyStay mobile app lets hospitalized patients and their families view lab results, see photos of their clinical team, review their care plans, and organize and prepare questions. FastTrack Innovation in Technology Program, Boston Children's Hospital

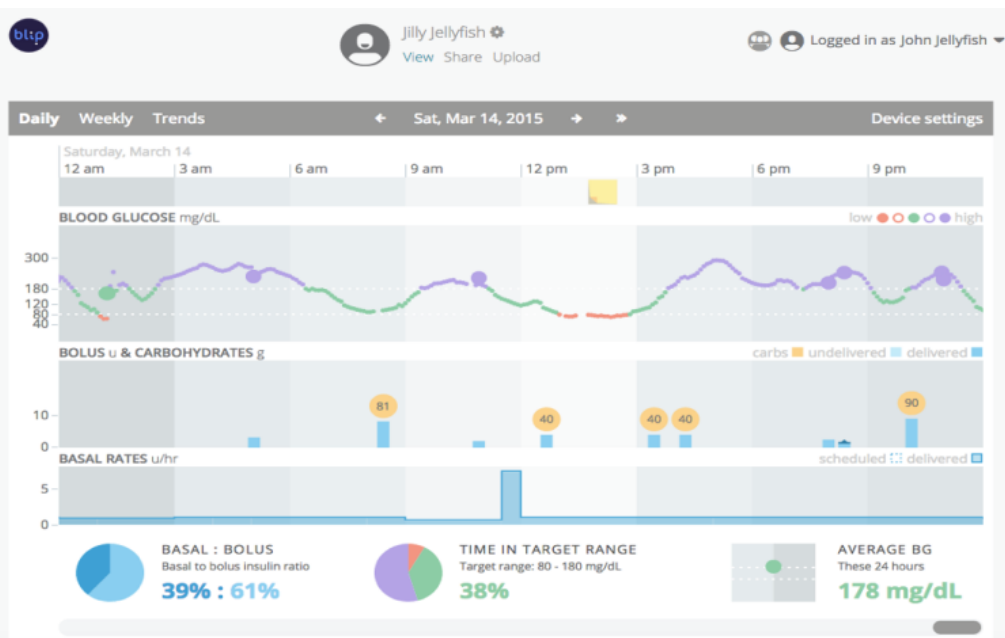




\section{Reimagining Health IT}

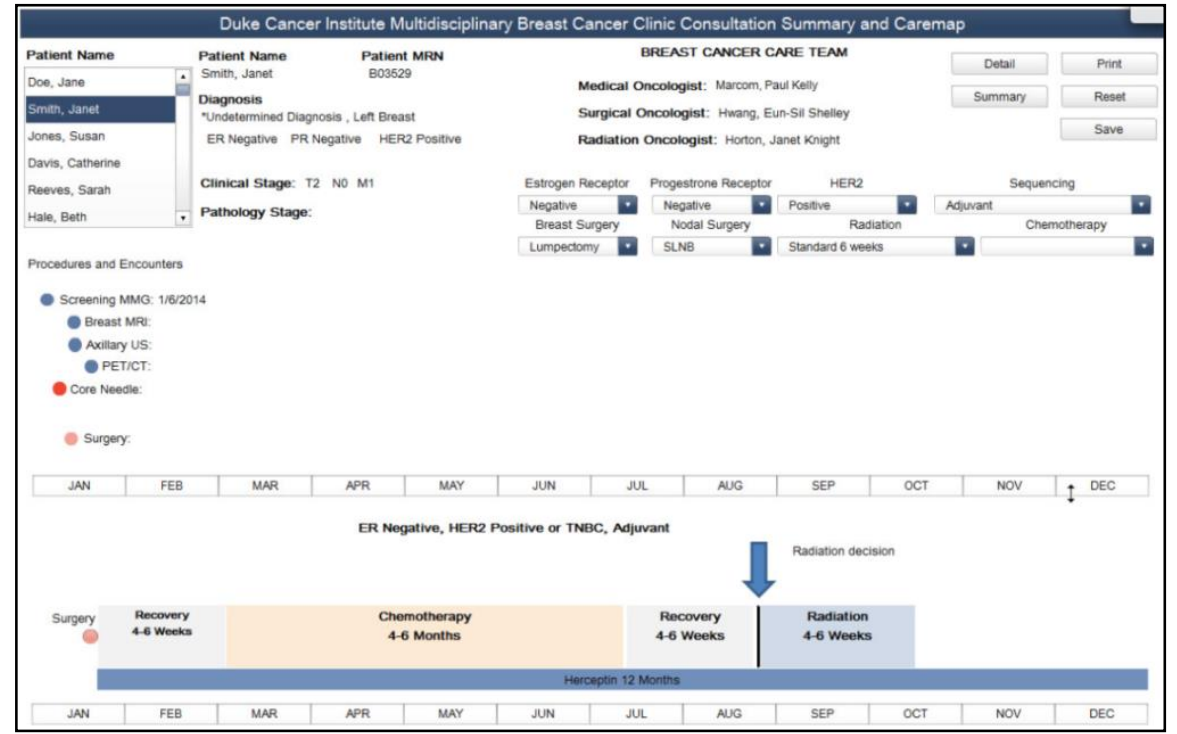

Breast cancer care maps-drawn from electronic medical records and other clinical data sources-summarize each patient's treatment plan. Accessible to both patients and providers, the maps seek to improve communication and enable better coordination of services and measurement of outcomes.

Duke Institute for Health Innovation, Duke University

An effort to reimagine how clinicians use electronic health record systems, for example by finding new and less disruptive ways of documenting clinical encounters and using data visualizations to help present "what we need to know and what we can do."

Szollosi Healthcare Innovation Program, affiliated with Northwestern Memorial Healthcare

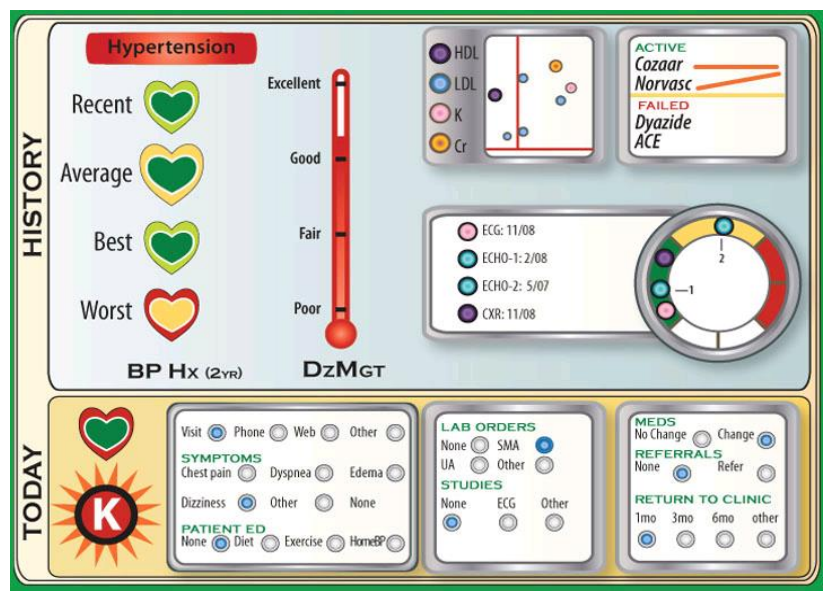

Note: Projects selected and categorized by authors, drawn from examples provided by innovation centers of projects that best illustrate their approach. 


\section{Clinical Workforce}

Use of care coordinators in primary care clinics to help patients understand their care plans and treatment instructions, support behavior modification, facilitate communication with clinic staff and clinicians between visits, and promote use of community resources. The coordinators are predominately nonlicensed staff from a variety of backgrounds, including medical assistants. They work solely in the clinics, and focus on high-risk patients identified by registries, clinic staff, and physicians in daily huddles. Institute for Innovation in Health, UCLA Health

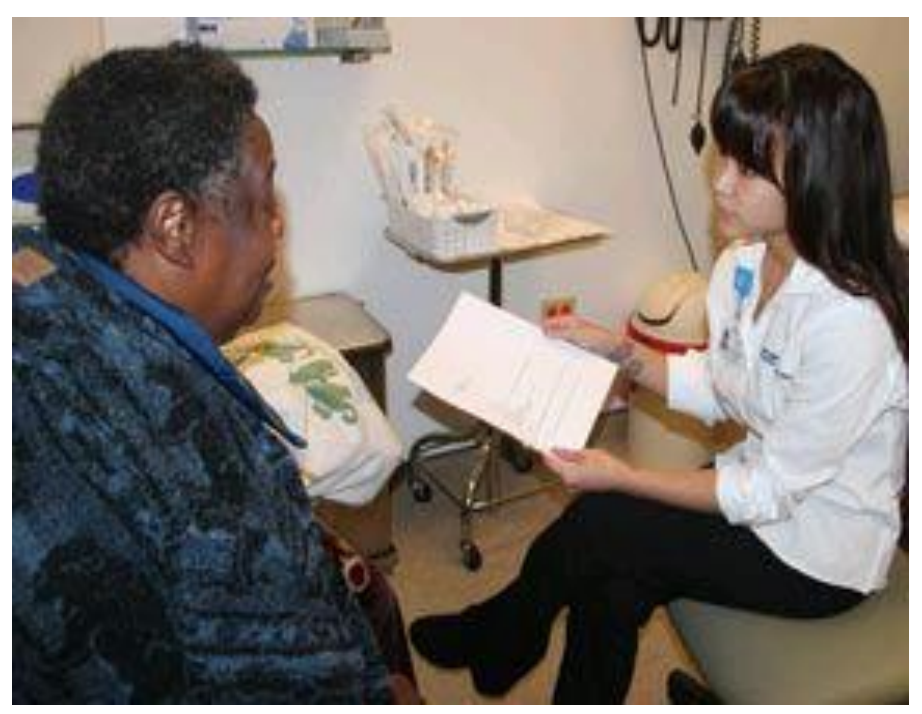

